\title{
Influence of Mo on microstructure and nanoindentation hardness of Ti-Al-Si-xMo alloy processed by Laser Engineered Net Shaping (LENS)
}

\author{
SA Rajia,b,", API Popoolaa, SL Pityanac, OM Popool ${ }^{d}$, NKK Arthurc, M Tlotlengc,e \\ ${ }^{a}$ Department of Chemical, Metallurgical and Materials Engineering, Tshwane University of Technology, Staatsartillerie Road, Pretoria West, \\ Pretoria, South Africa \\ ${ }^{b}$ Department of Metallurgical Engineering, Yaba College of Technology, P.M.B. 2011 Yaba, Lagos, Nigeria \\ 'National Laser Centre, Council for Scientific and Industrial Research, Meiring Naudé Road, Brummeria, Pretoria 0184, South Africa \\ ${ }^{d}$ Department of Electrical Engineering, Centre for Energy and Electric Power (CEEP), Tshwane University of Technology, Staatsartillerie Road, \\ Pretoria West, Pretoria, South Africa \\ eDepartment of Mechanical Engineering Science, University of Johannesburg, Auckland Park Campus, Johannesburg, South Africa \\ Email:RajiSA@tut.ac.za; rajisadiqa@gmail.com
}

\begin{abstract}
In this work, the microstructure and nanoindentation hardness properties of Ti-Al-Si-xMo alloys produced through laser in-situ alloying using laser engineered net shaping (LENS) technology were investigated. The microstructures and phases present were examined by means of scanning electron microscopy (SEM) equipped with an electron dispersion spectrometer (EDS), while the mechanical properties were studied using a nanoindentation tester. The microstructures exhibited fine lamellar $\alpha_{2}-\mathrm{Ti}_{3} \mathrm{Al} / \gamma$-TiAl colonies surrounded with $\zeta-\mathrm{Ti}_{5} \mathrm{Si}_{3}$ and ordered $\beta_{0}$-TiAl phase in the as-produced state; while after heat treatments coarse $\beta_{0}$-phase was observed to be embedded within the lamellae colonies. Microstructural analysis showed that $\beta_{0}$-phase precipitated not only at the $\alpha_{2} / \gamma$ lamellae colony boundaries but also inside the lamellae owing to the relatively high content of the $\beta_{0}$-phase present. Nanoindentation testing showed that the indentation hardness of this current alloy is comparable to most TiAl alloys. This study also reveals that Mo additions generally increase hardness values, but only minor effects on hardness are observed at $1400{ }^{\circ} \mathrm{C}$ heat treatment temperature. Thus, Mo additions for TiAl alloys demonstrate positive effects on mechanical properties when less than 5 at. $\%$ of the alloy composition but the mechanical properties would either reduce or remains unchanged with further increase in Mo.
\end{abstract}

Keywords: Laser Engineered Net Shaping (LENS); Composites; Gamma-Titanium Aluminides ( $\gamma$-TiAl); Additive Manufacturing; Phase Transformations; Titanium Silicide $\left(\zeta-\mathrm{Ti}_{5} \mathrm{Si}_{3}\right)$

\section{Introduction}

Additive manufacturing (AM) offers the benefits of higher productivity in contrast to conventional manufacturing routes (Svetlizky et al. 2020). A directed energy deposition (DED) AM technology known as laser engineered net shaping (LENS) belongs to this class of technologies. Materials such as metals, composite, ceramics, and functionally graded materials (FGM) including titanium aluminide-based (TiAl-based) alloys have been successfully processed by LENS technique (Raji et al. 2019, 2020; Svetlizky et al. 2020). In spite of this feat achieved with several alloys, fabricating superior engineering structures of TiAl intermetallic alloys is highly problematic.

This problem mainly relates to the inherent properties of TiAl being prone to high stress-induced cracking (Raji et al. 2019, 2020, 2021). This is caused by high cooling rates in AM technologies that easily induce cracks, while accumulation of excessive thermal energy through processing also results in the development of other defects like porosities (Raji et al. 2019, 2020, 2021; Svetlizky et al. 2020). Moreover, the lightweight nature of TiAl alloys with density of about $3.8 \mathrm{~g} / \mathrm{cm}^{3}$ still makes them desirable for airplane engine components (Gao and Wang, 2021; Oehring et al. 2021; Raji et al.
2021). Also, TiAl-based alloys possess excellent properties such as high strength-to-weight ratio, high strength retention at elevated temperatures, excellent high-temperature stiffness, low density and good creep properties (Raji et al. 2020, 2021; Xu et al. 2020). These attractive mechanical properties give a high prospect to TiAlbased in substituting the heavier nickel-based superalloys typically applied in producing turbine parts of aircraft engines (Kim et al. 2019; Raji et al. 2020; Xu et al. 2020). Nevertheless, inadequate hot workability is still a foremost issue regarding TiAl alloys which has led to a lot of interests from researchers in trying to mitigate the associated drawbacks confronting the wider application of these type of material.

These difficulties encountered play a considerable role in limiting the advancement of suitable TiAl intermetallic alloys produced by most AM technologies. Generally, the main method for eliminating cracks and preventing cracking is high-temperature preheating to enhance formability of TiAl based alloys processed through LENS (Raji et al. 2019, 2020; Svetlizky et al. 2020). Several authors have also suggested micro-alloying addition such as molybdenum (Mo), niobium $(\mathrm{Nb})$, chromium $(\mathrm{Cr})$ and silicon $(\mathrm{Si})$ can help improve TiAl's mechanical properties (Gao and Wang, 2021; Imayev et al. 2021; Mathabathe et al. 2021; Siahboumi et al. 2021; Raji et 
al. 2020; Xu et al. 2020). To date, only cast TiAl alloys processed through hot isostatic pressing (HIP) with subsequent heat treatment is proving to yield considerable positive results. Meanwhile, the HIP is a post-processing step that is expensive to realize and extending production time. Thus, to produce fully dense parts that are pore and crack-free there is the need to control the processing involved in AM technologies (Raji et al. 2020, 2021).

In our previous study (Raji et al. 2021), the microstructure and mechanical properties of ternary Ti-Al-Si alloy produced through in-situ laser processing using the LENS machine was investigated. Moreover, various researchers have investigated different type of $\gamma$-TiAl based alloys such as Ti-45Al (Oehring et al. 2021), Ti48Al6NbxSi alloys (Xu et al. 2020), Ti-48Al-2Cr-2Nb (Siahboumi et al. 2021), Ti-44Al-0.2B (Imayev et al. 2021), Ti44Al-5Nb-0.2B (Imayev et al. 2021), Ti-44Al-5Zr-0.2B (Imayev et al. 2021), Ti-44Al-2.5Zr-2.5Hf-0.2B (Imayev at al. 2021), Ti-Al$\mathrm{Nb}-\mathrm{Mo}$ (Staron et al. 2021), Ti-42Al-8.5Nb (Gabrisch et al. 2020) and $\mathrm{Ti}-42.9 \mathrm{Al}-4.6 \mathrm{Nb}-2 \mathrm{Cr}(\mathrm{Xu}$ and $\mathrm{Li}, 2021)$ (all compositions are in atomic percent unless stated otherwise) consisting mainly of either two phases $\alpha / \alpha_{2}$ and $\gamma$ or three phases $\alpha / \alpha_{2}, \beta / \beta_{0}$ and $\gamma$. Apart from the $\alpha / \alpha_{2}, \gamma$ and $\beta / \beta_{0}$ phases formed by TiAl-based alloys, special phases such as titanium silicide $\left(\zeta-\mathrm{Ti}_{5} \mathrm{Si}_{3}\right)$ and $\omega_{0}$ (TiAl) phases have been observed in certain case studies. But there are limited or no literature and information on the effects of Mo additions on ternary Ti-Al-Si alloys.

The principal rationale for the acceptance and the extensive investigation of TiAl alloys containing $\mathrm{Si}$ is the refinement of microstructure, increased melt pool wettability and reduction of shrinkages (Raji et al. 2020; Xu et al. 2020). These occurrences were ascribed to the particle size of $\mathrm{Si}$, distribution and variation at the grain boundaries of lamellae colonies (Raji et al. 2020), thus, variations in the microstructural morphology. In this present study, the effects of Mo on the nano-hardness properties and microstructural evolution of ternary Ti-Al-Si alloys are examined. This work presents Ti-Al-Si-xMo alloys developed by in-situ powder deposition using the LENS process and subsequent analysis of the microstructure and nanoindentation hardness properties of the heat-treated and as-build alloys.

\section{Materials and Experimental Procedure}

The experimental setup and parameters used in this study is similar to that of Raji et al. (2021) and Tlotleng (2019), with slight modification including the feed rate for Mo. The parameters used to develop the alloys are highlighted in Table 1. The alloy samples were fabricated using elemental powders of titanium (Ti), aluminium (Al), silicon $(\mathrm{Si})$ and molybdenum $(\mathrm{Mo})$ to produced cubes of $15 \mathrm{~mm}$ by $15 \mathrm{~mm}$ by $10 \mathrm{~mm}$ coupons. All the powders had particle size range of $45-90 \mu \mathrm{m}$ that were fed by two powder feeders of the Optomec 850R LENS machine (for Ti and Al) with two externally attached GTV powder feeders (for the Si and Mo). This system makes our experimental setup a modified LENS four powder hopper delivery system. The powder was co-axially deposited on the Ti6Al4V metal substrate to produce an in-situ TiAl-Si-xMo alloy after the chamber had been purged off by argon (Ar) gas to create an inert environment. The as-built sample were characterized before and after heat treatment with results presented the next section.

The heat treatment was carried out at $1200{ }^{\circ} \mathrm{C}$ and $1400{ }^{\circ} \mathrm{C}$ for 1 hour under Ar-rich environment in a Carbolite tube furnace and cooled in the furnace. The produced LENS Ti-Al-Si-xMo alloys were sectioned along direction of build, mounted in phenolic resin using an automatic mounting press. This was followed by manual grinding and automatic polishing with a Struers TegrsForce-5 auto/ manual polisher using the OP-S suspension fluid. Kroll's reagent having $92 \mathrm{ml}$ distilled water, $6 \mathrm{ml}$ nitric acid and $2 \mathrm{ml}$ hydrofluoric acid was used as etchant for making the microstructure visible during analysis. All the samples were studied with a scanning electron microscope (SEM) equipped with energy-dispersive spectroscope (EDS); this is a JOEL JSM-6010PLUS/LAM analytical SEM. The composition of the constituent elements of asbuilt and heat-treated Ti-Al-Si-xMo alloys are presented in Table 2. Nanoindentation hardness tester Anton-Paar TTX-NHT3 machine was used to investigate the mechanical properties of all the alloys. The nanoindentation tests carried out up to a maximum load of $200 \mathrm{mN}$ for a total time of 60 seconds per indents with the loading, holding and unloading time of 20 seconds each. The indentations results gave a representation of the samples' mechanical properties (Young Modulus, stiffness and indentation hardness). The Oliver and Pharr method was adopted for the analyzing the load displacement curve (Oliver and Pharr, 1992).

Table 1: Powder Deposition Feed Rates and Feeding Rates for LENS In-Situ Alloying Adopted from ref. (Raji et al. 2021) with Modification

\begin{tabular}{lccccc}
\hline Parameter & \multicolumn{2}{c}{ Values } & Sample 1 & Sample 2 \\
\hline Laser Power $(\mathrm{W})$ & \multicolumn{2}{c}{$450 \mathrm{~W}$} \\
Scan Speed $(\mathrm{mm} / \mathrm{s})$ & \multicolumn{2}{c}{$10.58 \mathrm{~mm} / \mathrm{s}$} & & \\
Centre Purge $(1 / \mathrm{min})$ & \multicolumn{2}{c}{$25 \mathrm{l} / \mathrm{min}$} \\
& Ti & Al & Si & Mo & Mo \\
\cline { 2 - 6 } Carrier gas (1/min) & 4.2 & 2.4 & 2.0 & 1.0 & 1.0 \\
$\begin{array}{l}\text { Powder Feed Rate } \\
(\mathrm{rpm})\end{array}$ & 1.5 & 2.5 & 0.1 & 0.1 & 0.2 \\
\hline
\end{tabular}

Table 2: Composition of the As-Built and Heat-Treated Ti-Al-Si-Mo Alloys (at.\%)

\begin{tabular}{lcccc}
\hline & Ti & Al & Si & Mo \\
\hline Sample 1 As-Build & 39.0 & 56.3 & 1.1 & 3.6 \\
Sample 1 $1200{ }^{\circ} \mathrm{C}$ & 38.4 & 56.7 & 1.3 & 3.6 \\
Sample 1 $1400{ }^{\circ} \mathrm{C}$ & 39.8 & 54.9 & 1.4 & 3.9 \\
\hline Sample 2 As-Build & 42.0 & 50.4 & 1.1 & 6.5 \\
Sample 2 $1200{ }^{\circ} \mathrm{C}$ & 39.6 & 52.3 & 0.9 & 7.2 \\
Sample 2 $1400{ }^{\circ} \mathrm{C}$ & 40.3 & 51.7 & 0.9 & 7.1 \\
\hline
\end{tabular}

\section{Results}

\subsection{Microstructure}

Figure 1 is the microstructure of as-built Ti-Al-Si-xMo alloys with the different additions of Mo. It was observed that the morphology of the Ti-Al-Si-xMo alloys changes from lamellae colonies and grain boundary silicide $\left(\zeta-\mathrm{Ti}_{5} \mathrm{Si}_{3}\right)$ with fine $\beta_{0}$-phase to coarse $\beta_{0}$ phases dominating as the Mo addition increases from 3.6 at.\% to 

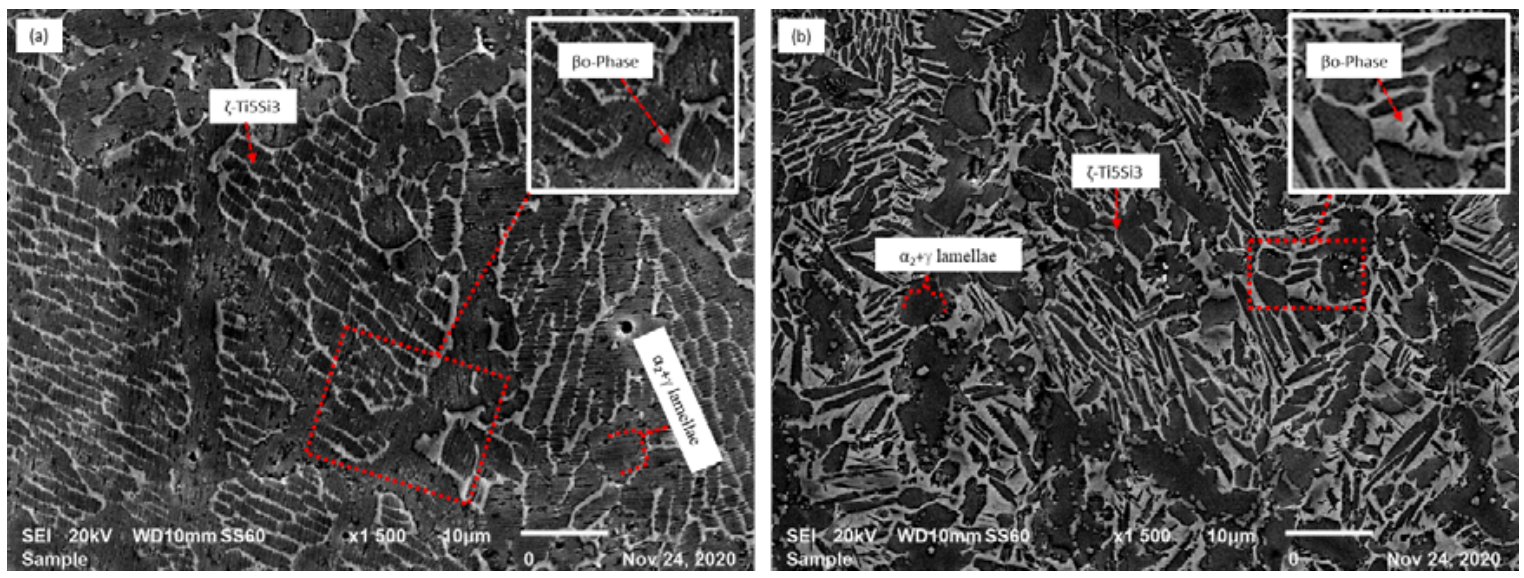

Figure 1: SEM image of Non Heat Treated (a) Sample 1 As-Built and (b) Sample 2 As-Built

6.5 at.\%. The composition of Ti-Al-Si-xMo alloys before and after heat treatment are summarized in Table 2. The Ti-Al-Si without the addition of Mo (refer to (Raji et al. 2020) shows lamellae $\left(\alpha_{2}+\gamma\right)$ colonies surrounded by $\zeta-\mathrm{Ti}_{5} \mathrm{Si}_{3}$ phases. The microstructure evolves to refined lamellar grains and fine thin $\beta_{0}$ formation with Mo addition, as shown in Figure 1(a). However, further addition of up to 6.5 at. $\%$ results in substantial coarsening of the $\beta_{0}$ phase since Mo is a very strong $\beta$ stabilizer.

Furthermore, examining the heat-treated samples in Figure 2 (a)-(d), sample 1 heat-treated at $1200{ }^{\circ} \mathrm{C}$ (Figure 2a), shows no decrease in Mo content which is evident in the microstructure being equiaxed grains of $\alpha_{2}+\gamma$ with visible reduction of the $\beta_{0}$-phase. But for sample 1 heat-treated at $1400^{\circ} \mathrm{C}$ (Figure $2 \mathrm{c}$ ), the $\beta_{0}$-phases starts to emerge without much change in the $\zeta-\mathrm{Ti}_{5} \mathrm{Si}_{3}$ phase and apparent large $\alpha_{2}+\gamma / \gamma$ lamellae grains. But Mo content increases from 6.5 at. $\%$ to 7.2 at. $\%$ with 7.1 at. $\%$ observed for heat-treated sample 2 .
Figures 2(b) and 2(d) shows less $\alpha_{2}+\gamma / \gamma$ lamellae grains sizes and significantly coarse $\beta_{0}$-phase dominating the microstructure with slight reduction of $\zeta-\mathrm{Ti}_{5} \mathrm{Si}_{3}$ phase.

Figures 3 and 4 shows the microstructure of Ti-Al-Si-xMo alloy SEM/EDS mapping of sample 2 as-built and heat-treated at 1400 ${ }^{\circ} \mathrm{C}$. The constituent elements and phases can easily be compared or mapped against the SEM micrographs with the different colours. It is observed that the bright region ( $\beta_{0}$ phase) is rich in Mo and $\mathrm{Ti}$; whereas the grey region is an Al-rich phase with less Mo in all the Ti-Al-Si-xMo alloys. No observed significant change in Mo content for the sample 1 alloys but sample 2 demonstrated a sharp rise in Mo after heat treatment suspected to be due to inability of the $\alpha_{2} / \gamma$ colonies to accommodate and dissolve higher amount of Mo leading to high volume of $\beta_{0}$-phase precipitation. This invariably reduces the amount of $\zeta-\mathrm{Ti}_{5} \mathrm{Si}_{3}$ phase and the $\alpha_{2} / \gamma$ colonies within the microstructure. Simultaneously, the content of Mo is increased
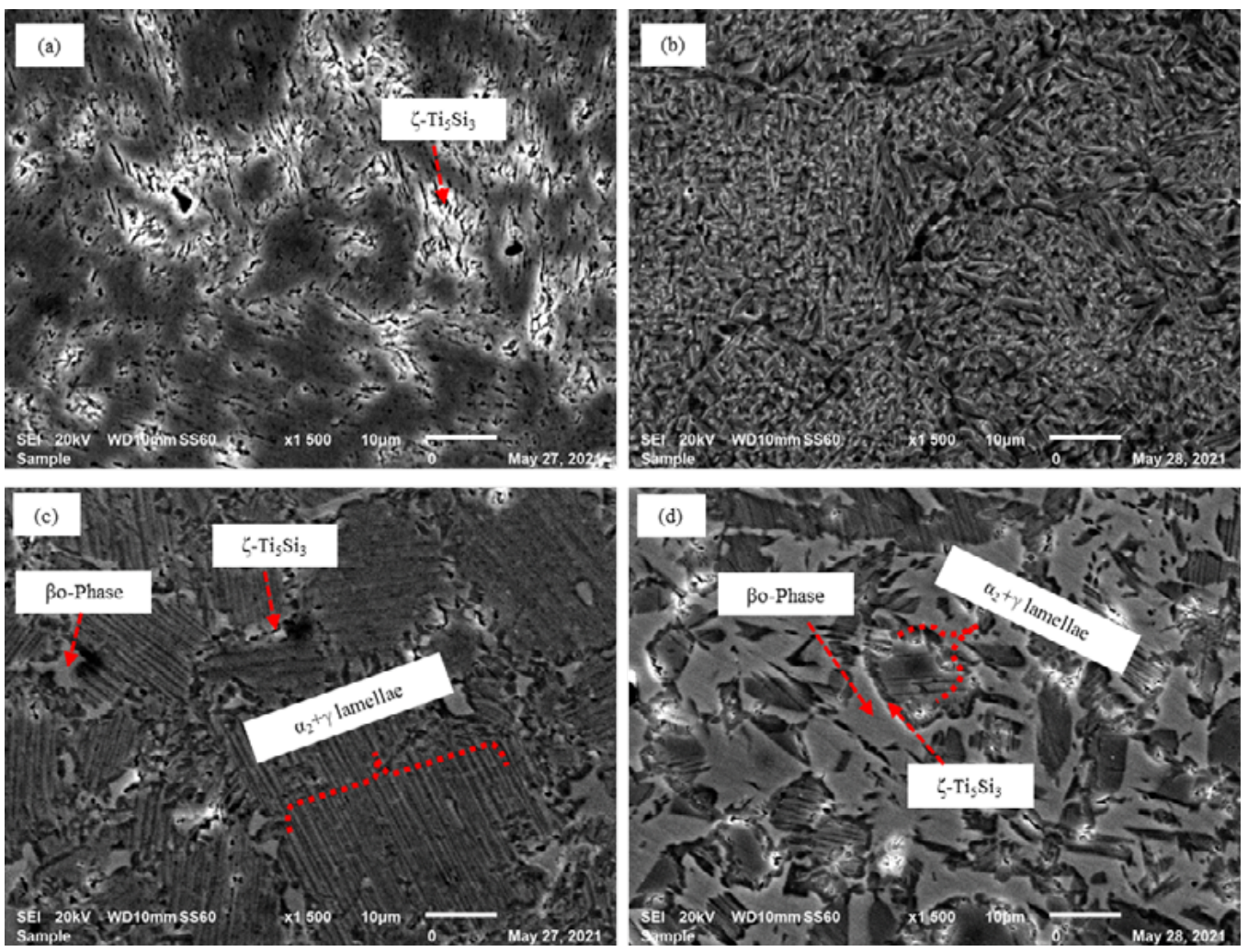

Figure 2: SEM image of Heat Treated (a) Sample $11200^{\circ} \mathrm{C}$, (b) Sample $21200{ }^{\circ} \mathrm{C}$, (c) Sample $11400{ }^{\circ} \mathrm{C}$, and (b) Sample $21400{ }^{\circ} \mathrm{C}$ 

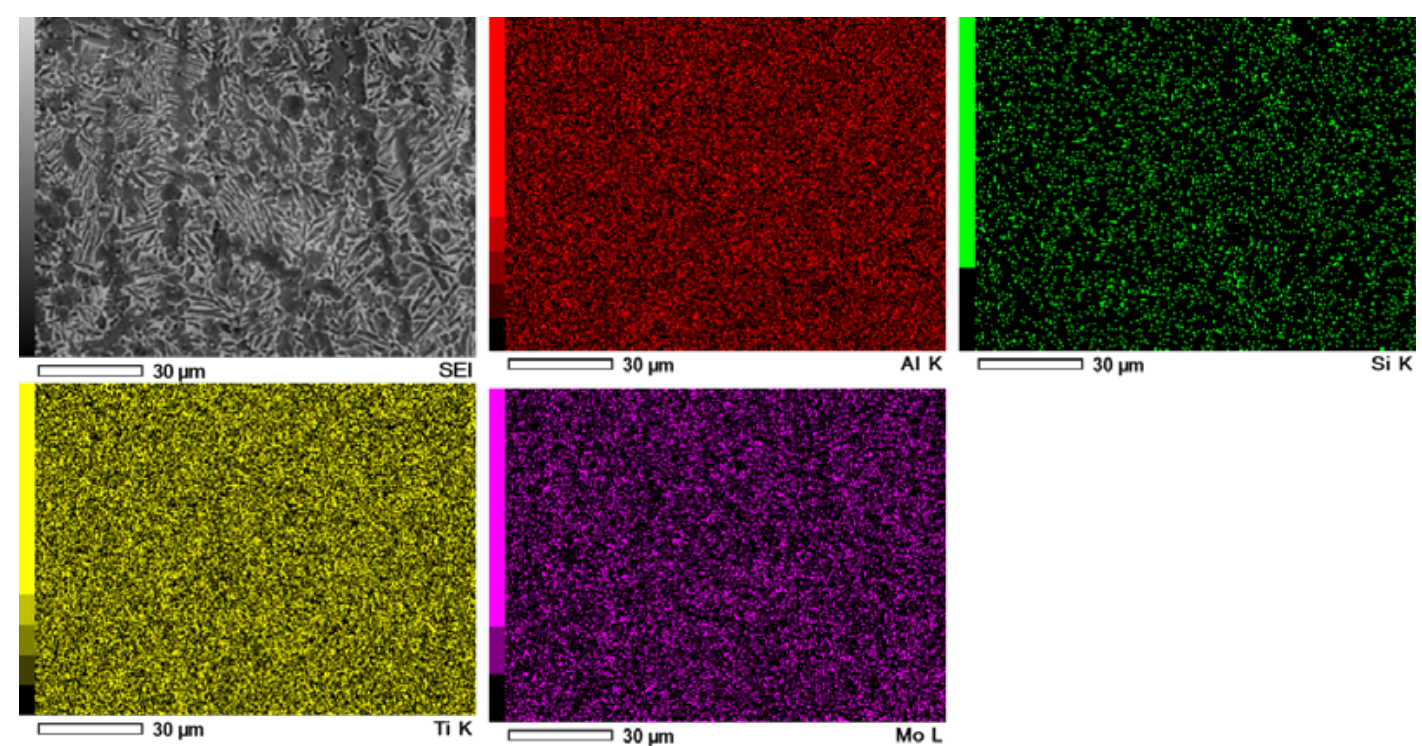

Figure 3: SEM/EDS Phase Mapping of Sample 2 As-Built
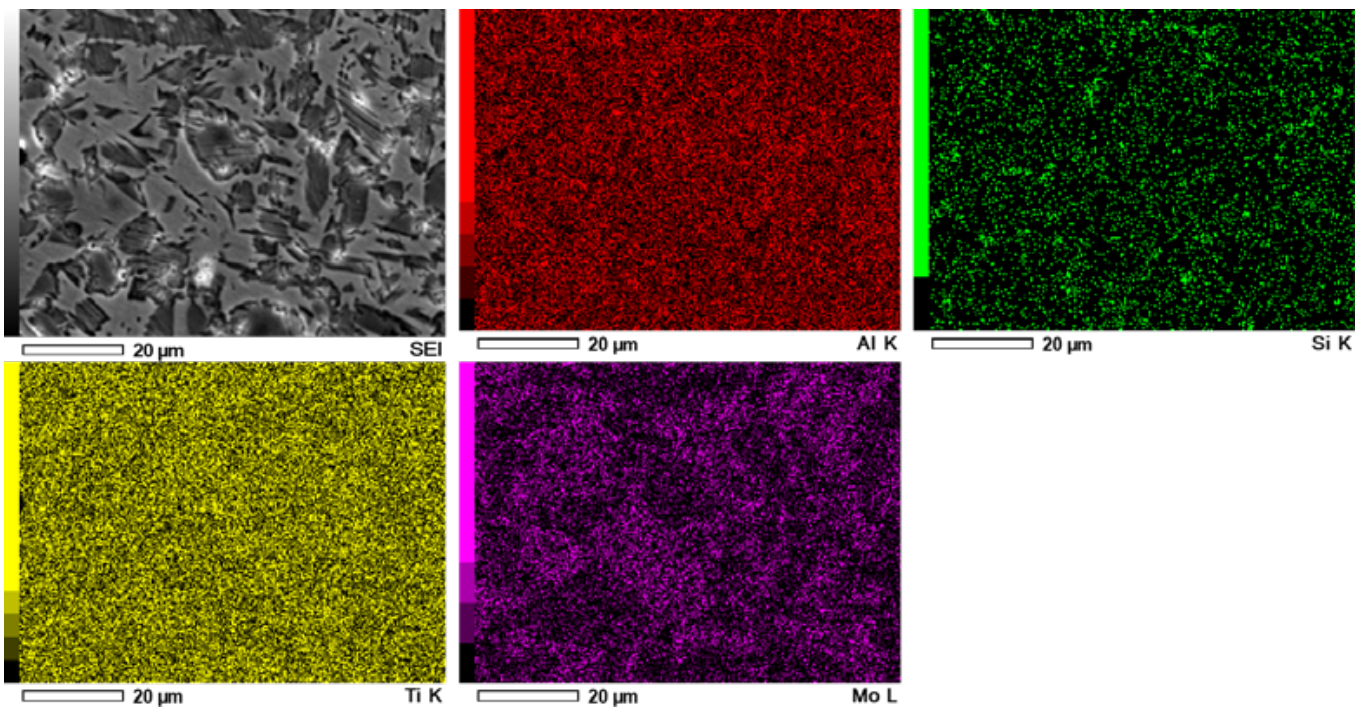

Figure 4: SEM/EDS Phase Mapping of Sample $21400^{\circ} \mathrm{C}$

in the grey regions, although certain amount of the Mo is dissolved by the $\zeta-\mathrm{Ti}_{5} \mathrm{Si}_{3}$ silicide phase.

The ordered $\beta_{0}$-phase is formed as a result of Mo being a strong $\beta$-stabilizer which segregates in lamellar between the lamellae colonies. However, Mo can be substituted by $\mathrm{Si}$ in the B2 structure, thereby increasing the amount Mo within the alloy matrix before the formation of $\zeta-\mathrm{Ti}_{5} \mathrm{Si}_{3}$ phase. Therefore, $\beta_{0}$-phase increases owing to no change or reduction in $\mathrm{Si}$ with increased addition of Mo forming more $\beta_{0}$-phase. In a study carried out by Xu et al. (2020), it was explained that $\zeta-\mathrm{Ti}_{5} \mathrm{Si}_{3}$ phase can dissolve certain amount of the $\beta$ stabilizers. Thus, since the addition of Si was kept constant as Mo was increases, this led to an obvious rise in the quantity of $\beta_{0}$-phase and decrease in $\zeta-\mathrm{Ti}_{5} \mathrm{Si}_{3}$ phase. Therefore, the total amount of Mo dissolved in $\zeta-\mathrm{Ti}_{5} \mathrm{Si}_{3}$ phase reduces and causes a rise in the ordered B2-structure ( $\beta_{0}$-phase) in the Ti-Al-Si-xMo alloys.

\subsection{Nanoindentation}

The mechanical properties measured by nanoindentation of the asbuilt and heat-treated Ti-Al-Si-xMo alloys with different additions of Mo are presented in Figures 5-7. The indentation hardness (Figure 5) of sample 1 increases with the heat treatment temperatures while that of sample 2 shows an initial rise in nanoindentation hardness value ( 8327 to $14608 \mathrm{MPa}$ ) when heat treated at 1200 ${ }^{\circ} \mathrm{C}$. There was no notable difference between $1400{ }^{\circ} \mathrm{C}$ and 1200 ${ }^{\circ} \mathrm{C}$ heat-treated sample 2. Thus, indentation hardness of Ti-Al-SixMo alloys increases with increased Mo content; while in Figure 6, stiffness and Young's Modulus shows an inverse relationship to the Mo content. For sample 1, the stiffness steadily reduces from 1.16 $\mathrm{mN} / \mathrm{nm}$ to $1.08 \mathrm{mN} / \mathrm{nm}$ to $0.9756 \mathrm{mN} / \mathrm{nm}$ for the as-built, 1200 ${ }^{\circ} \mathrm{C}$ and $1400{ }^{\circ} \mathrm{C}$ heat treatment, respectively. However, for sample 2 with a higher Mo content, the Young's Modulus and stiffness values initially rise when heat-treated at $1200{ }^{\circ} \mathrm{C}$ then slightly drops for $1400^{\circ} \mathrm{C}$ heat treatment temperature.

Figure 7 shows the indentation hardness and the Young's Modulus of samples 1 and 2 as-built and heat-treated at $1200{ }^{\circ} \mathrm{C}$ and 1400 ${ }^{\circ} \mathrm{C}$. Although, the hardness values increase for sample 1 as-built (8913 MPa) to $1200{ }^{\circ} \mathrm{C}(1027 \mathrm{MPa})$ and $1400{ }^{\circ} \mathrm{C}(1079 \mathrm{MPa})$, the Young's Modulus does not follow the same pattern. Rather, it rises 
from $203 \mathrm{GPa}$ to $209 \mathrm{GPa}$ for the as-built to $1200^{\circ} \mathrm{C}$, respectively, but then reduces to $193 \mathrm{GPa}$ when heat-treated at $1400{ }^{\circ} \mathrm{C}$; this same trend was also observed for the Young's Modulus in sample 2 while there was no change in the indentation hardness for the heattreated sample 2. Consequently, Mo tends to generally increase the hardness of the Ti-Al-Si-xMo alloys while reducing the stiffness and Young's Modulus. But $1200{ }^{\circ} \mathrm{C}$ heat treatment temperature

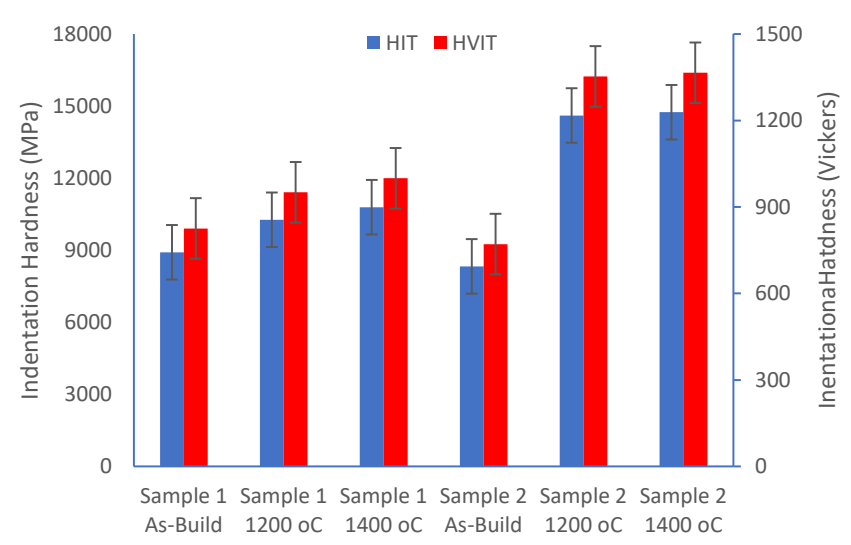

Figure 5: Showing the Indentation Hardness in MPa and Vickers Indentation Hardness of both Samples 1 and Sample 2 As-Built and Heat Treated at $1200{ }^{\circ} \mathrm{C}$ and $1400{ }^{\circ} \mathrm{C}$

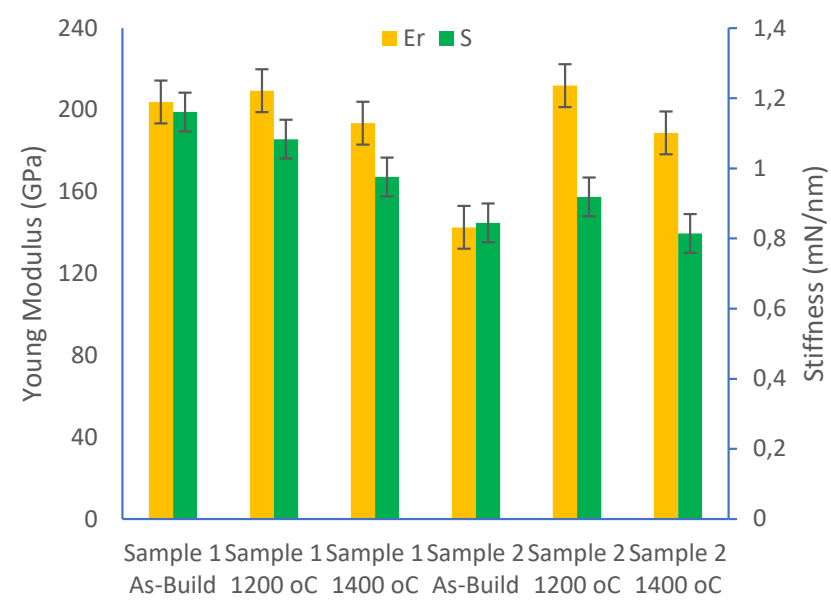

Figure 6: Showing the Young Modulus and the Stiffness of both the Samples 1 and Sample 2 As-Built and Heat Treated at $1200^{\circ} \mathrm{C}$ and $1400{ }^{\circ} \mathrm{C}$

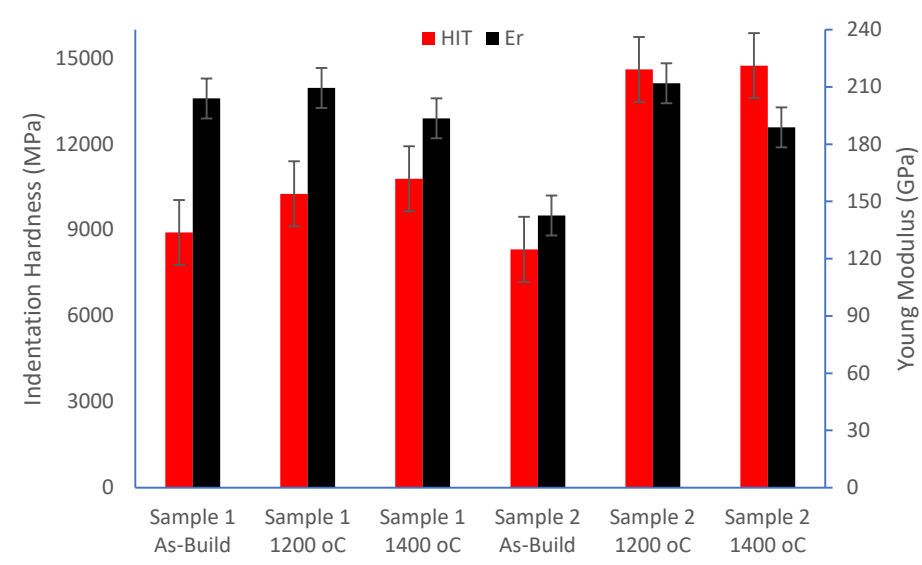

Figure 7: Indentation hardness and Young's Modulus of both the Samples 1 and Sample 2 as-built and Heat Treated at $1200{ }^{\circ} \mathrm{C}$ and 1400 ${ }^{\circ} \mathrm{C}$ increases both the hardness and Young's Modulus of Ti-Al-Si-xMo alloys.

\section{Discussion}

The aforementioned phenomenon of rise in indentation hardness and Young's Modulus for sample 1 and 2 heat-treated at $1200{ }^{\circ} \mathrm{C}$ was credited to an increase in $\beta_{0}$ and $\zeta-\mathrm{Ti}_{5} \mathrm{Si}_{3}$ phase precipitation with lesser $\gamma$-phase within the microstructure especially the lamellae grains.

As stated above, the Si helps in the dissolution of Mo in the TiAl-Si-xMo alloys and $\zeta-\mathrm{Ti}_{5} \mathrm{Si}_{3}$ phase is formed at the lamellae colonies' interfaces of the Ti-Al-Si-xMo alloys. This occurs as a result of limited solubility of Si in the $\alpha_{2} / \gamma$ lamellae grains (Raji et al. 2020; Xu et al. 2020). This has a propensity to align the precipitates at the lamellar interfaces especially for TiAl alloys that have low $\alpha_{2}$-phase content after being heat-treated within the dual-phase region of the phase diagram. This is also hindered by the $\beta_{0}$ phase formation owing to Mo strong affinity for stabilizing the ordered $\beta_{0}$-phase. Hence, the Mo causes more precipitation and stability of the $\beta_{0}$-phase leading to segregated areas; while $\zeta-\mathrm{Ti}_{5} \mathrm{Si}_{3}$ phase is also formed at the interface of the lamellae colonies (Raji et al. 2020, 2021; Xu et al. 2020).

As observed in Figure 1, when the content of Mo is increased from 3.7 at. $\%$ to 6.5 at. $\%, \beta_{0}$ phase which has a higher solubility for Mo is more visible. Also, this $\beta_{0}$-phase forces Si to migrate from $\beta_{0}$-phase region into the matrix (Xu et al. 2020). However, due to lack of Si dissolution in the $\gamma$-phase, $\zeta-\mathrm{Ti}_{5} \mathrm{Si}_{3}$ precipitates begin to appear as the $\alpha_{2}$-phase that has high solubility for Si is saturated. Thus, causing a reduction in the amount of $\alpha_{2}$-phase within the microstructure. Meanwhile, after the heat treatments (Figures 2-4) large amount of the $\alpha_{2}$ phase with $\beta_{0}$-segregation are formed. The $\alpha_{2} / \gamma$ lamellae is formed through solid-state phase transformation to residual $\beta_{0}$-phases and subsequently transforms into coarse $\beta_{0}$ from the $\alpha_{2}$-phase with embedded $\zeta-\mathrm{Ti}_{5} \mathrm{Si}_{3}$ phases at the grain boundary sites. Consequently, the Ti-Al-Si-xMo alloys microstructure consists of $\alpha_{2} / \gamma$ lamellae, $\zeta-\mathrm{Ti}_{5} \mathrm{Si}_{3}$ and $\beta_{0}$-phase; while the sample 2 with high content of Mo exhibits coarsened plate-like $\beta_{0}$-phase.

The heat-treated sample 2 shows significant $\beta_{0}$-phase formation having higher content of Mo and the $\alpha_{2}$-phase with $\beta_{0}$-segregation is transformed through a peritectic reaction ( $\mathrm{Xu}$ et al. 2020). The segregation of Mo atoms in $\alpha_{2}$-phase and $\mathrm{Si}$ atoms is constricted between the grain boundaries of the lamellae colonies. The $\zeta-\mathrm{Ti}_{5} \mathrm{Si}_{3}$ phase is then formed at the interfaces of the grain boundary leading to $\mathrm{Si}$ at.\% decreasing. Finally, the Ti-Al-Si-xMo alloy microstructure results in extensive $\beta_{0}$ phase precipitation with overall rise in the Mo content.

Figures 5-7 shows that the formation of $\zeta-\mathrm{Ti}_{5} \mathrm{Si}_{3}$ and $\beta_{0}$-phase leads to the increase of indentation hardness and a reduction of stiffness and Young's Modulus for sample 1 of the Ti-Al-SixMo alloys. While sample 2 demonstrates little or no change in Young's Modulus and indentation hardness after heat treatment but the stiffness initially rises after heat treatments temperature of $1200{ }^{\circ} \mathrm{C}$ and decreases at $1400{ }^{\circ} \mathrm{C}$. Since $\mathrm{Si}$ behaves as a solid solution strengthening atom in the Ti-AlSi-xMo alloys, Si decreases the amount of initial $\beta_{0}$-phase. 
The Young's Modulus of the sample 1 for the heat-treated and the as-built were relatively close. However, an increase in Mo content as the quantity of Si during in-situ alloying was unchanged, this was suggested to be responsible for the drastic increase in Young's Modulus of heat-treated sample 2 at $1200{ }^{\circ} \mathrm{C}$. Moreover, the slight reduction of the Young's Modulus of heat-treated sample 2 at 1400 ${ }^{\circ} \mathrm{C}$ was due to the formation of more $\alpha_{2} / \gamma$ lamellae. Whereas, the $\mathrm{Si}$ atoms interstitial behaviour leads to the distortion of the alloy lattice structure. This would cause resistance to dislocation motion making the deformation of this alloys very problematic, thus, reduction in stiffness and modulus of the Ti-Al-Si-xMo alloys. In this alloying system, the precipitation of the $\zeta-\mathrm{Ti}_{5} \mathrm{Si}_{3}$ phase acts as a secondary phase and displays a secondary phase strengthening mechanism in this alloy (Raji et al. 2021; Xu et al. 2020). With continual rise of Mo, the amount of $\beta_{0}$ phase increases while that of $\zeta-\mathrm{Ti}_{5} \mathrm{Si}_{3}$ phase reduces. Thus, the strengthening mechanism by the secondary phase was affected when $\zeta-\mathrm{Ti}_{5} \mathrm{Si}_{3}$ begins to reduce at the $1400^{\circ} \mathrm{C}$ heat treatment temperature. Therefore, the mechanical properties (stiffness, indentation hardness and young modulus) either reduces or remains unchanged with increasing Mo contents

\section{Conclusions}

In this paper, Ti-Al-Si-xMo alloys were produced via LENS insitu alloying and the microstructural evolution and nanoindentation hardness of these alloys were methodically examined. Some deductions observed are as follows:

- Mo additions gives rise to increased coarsening of the $\beta_{0}$-phase at the $\alpha_{2} / \gamma$ lamellae interfaces and grain boundary silicide $\left(\zeta-\mathrm{Ti}_{5} \mathrm{Si}_{3}\right)$.

- The Ti-Al-Si-xMo alloys microstructure consists of $\alpha_{2} / \gamma$ lamellae, $\zeta-\mathrm{Ti}_{5} \mathrm{Si}_{3}$ and $\beta_{0}$-phase; while the sample 2 having a higher content of Mo had coarse plate-like $\beta_{0}$-phase. Additionally, formation of $\zeta-\mathrm{Ti}_{5} \mathrm{Si}_{3}$ phase reduces the amount of Mo the alloy matrix can dissolved

- The increase of indentation hardness and a reduction of stiffness and Young's Modulus was observed for sample 1; while sample 2 demonstrates little or no change in Young's Modulus and indentation hardness after heat treatment but the stiffness initially rises after heat treatments temperature of $1200{ }^{\circ} \mathrm{C}$ and decreases at $1400{ }^{\circ} \mathrm{C}$.

- Mo tends to generally increase the Ti-Al-Si-xMo alloys nanoindentation hardness while reducing stiffness and Young's Modulus. But $1200{ }^{\circ} \mathrm{C}$ heat treatment temperature increases both the hardness and Young's Modulus of Ti-Al-Si-xMo alloys. Also, $\zeta-\mathrm{Ti}_{5} \mathrm{Si}_{3}$ phase strengthening mechanism begins to reduce at the $1400{ }^{\circ} \mathrm{C}$ heat treatment temperature.

- Generally, Mo addition is beneficial up to 5 at.\% of the alloy composition but the mechanical properties (stiffness, indentation hardness and young modulus) either reduces or remains unchanged by further increasing the Mo content.

\section{Acknowledgments}

The authors would like to acknowledge the financial support (scholarship grant) from the African Laser Centre-National Laser Centre; Council of Scientific and Industrial Research (ALC-NLC; CSIR), Project Number LHIP500 Task ALC S100.

\section{ORCID}

Sadiq Abiola RAJIa

https://orcid.org0000-0003-1613-1825

Abimbola Patricia Idowu POPOOLA

https://orcid.org0000-0003-4447-8551

Sisa Lesley PITYANA

https://orcid.org0000-0002-9273-2043

Olawale Muhammed POPOOLA

https://orcid.org0000-0002-9980-5241

Nana Kwamina Kum ARTHUR

https://orcid.org0000-0001-8400-329X

Monnamme TLOTLENG

https://orcid.org0000-0003-2548-2598

\section{References}

1. Gabrisch, H., Krekeler, T., Lorenz, U., Rackel, M.W., Ritter, M., Pyczak, F. and Stark, A., 2020. Phase separation and up-hill diffusion in the ordered $\alpha 2$ compound of a $\gamma$-Ti-Al-Nb alloy. In: The 14th World Conference on Titanium, MATEC Web of Conferences, 321, 12041. https://doi.org/10.1051/matecconf/202032112041

2. Gao, P. and Wang, Z., 2021. Formability improvement, cracking behavior and control of Y-modified Ti-43Al-4Nb-1Mo$0.1 \mathrm{~B}$ alloys produced by selective laser melting. Journal of Alloys and Compounds, 854, 157172. https://doi.org/10.1016/j. jallcom.2020.157172

3. Imayev, V.M., Ganeev, A.A., Trofimov, D.M., Parkhimovich, N.J. and Imayev, R.M., 2021. Effect of $\mathrm{Nb}, \mathrm{Zr}$ and $\mathrm{Zr}+\mathrm{Hf}$ on the microstructure and mechanical properties of $\beta$-solidifying $\gamma$-TiA alloys. Materials Science and Engineering: A, 817, 141388. https:// doi.org/10.1016/j.msea.2021.141388

4. Kim, Y.K., Youn, S.J., Kim, S.W., Hong, J. and Lee, K.A., 2019 High-temperature creep behavior of gamma Ti-48Al-2Cr-2Nb alloy additively manufactured by electron beam melting. Materials Science and Engineering: A, 763, 138138. https://doi.org/10.1016/j. msea.2019.138138

5. Mathabathe, M.N., Modiba, R. and Bolokang, A.S., 2021. The effects of quaternary alloying additions on the $\gamma \mathrm{TiAl}$ alloy: Preferential site occupancy, interfacial energetics to physical parameters. Surfaces and Interfaces, 25, 101173. https://doi.org/10.1016/j.surfin.2021.101173

6. Oehring, M., Matthiessen, D., Blankenburg, M., Schell, N. and Pyczak, F., 2021. An in situ high-energy synchrotron X-ray diffraction study of directional solidification in binary TiAl alloys. Advanced Engineering Materials, 2100151. https://doi.org/10.1002/ adem.202100151

7. Oliver, W.C. and Pharr, G.M., 1992. An improved technique for determining hardness and elastic modulus using load and displacement sensing indentation experiments. Journal of materials research, 7(6), 1564-1583. https://doi.org/10.1557/JMR.1992.1564

8. Raji, S.A., Popoola, A.P.I., Pityana, S.L., Popoola, O.M., Aramide, F.O., Tlotleng, M. and Arthur, N.K.K., 2019. Laser based additive manufacturing technology for fabrication of titanium aluminidebased composites in aerospace Component Applications. In: Mofid Gorji-Bandpy, $M$ and Aly, A (Eds), Aerodynamics 2019, IntechOpen. London, pp. 193-218. https://doi.org/10.5772/intechopen.85538

9. Raji, S.A., Popoola, A.P.I., Pityana, S.L. and Popoola, O.M., 2020 Characteristic effects of alloying elements on $\beta$ solidifying titanium aluminides: A review. Heliyon, 6(7), e04463. https://doi.org/10.1016/j. heliyon.2020.e04463

10. Raji, S.A., Popoola, A.P.I., Pityana, S.L. and Tlotleng, M., 2021 Microstructure and mechanical properties of heat-treated Ti-Al-Si alloy produced via laser in situ alloying. Journal of Materials Engineering and Performance, 30(5), 3321-3332. https://doi. org/10.1007/s11665-021-05681-9

11. Siahboumi, A.A., Kermanpur, A., Sadeghi, F. and Ghorbani, H.R., 2021. Effect of Hf addition on solidification and hot isostatically pressed microstructures of the Ti-48Al-2Cr-2Nb (at $\%)$ intermetallic alloy. Journal of Alloys and Compounds, 860, 158437. https://doi. org/10.1016/j.jallcom.2020.158437

12. Staron, P., Stark, A., Schell, N., Spoerk-Erdely, P. and Clemens, H., 2021. Thermal expansion of a multiphase intermetallic Ti-Al-Nb-Mo 
alloy studied by high-energy X-ray diffraction. Materials, 14(4), 727. https://doi.org/10.3390/ma14040727

13. Svetlizky, D., Zheng, B., Buta, T., Zhou, Y., Golan, O., Breiman, U., Haj-Ali, R., Schoenung, J.M., Lavernia, E.J. and Eliaz, N., 2020. Directed energy deposition of Al 5xxx alloy using laser engineered net shaping (LENS®). Materials \& Design, 192, 108763. https://doi. org/10.1016/j.matdes.2020.108763

14. Tlotleng, M., 2019. Microstructural properties of heat-treated LENS in situ additively manufactured titanium aluminide. Journal of
Materials Engineering and Performance, 28(2), 701-708. https://doi. org/10.1007/s11665-018-3789-5

15. Xu, Q., Fang, H.Z., Wu, C., Wang, Q., Cui, H.Z. and Chen, R.R., 2020. Microstructure evolution and its effect on mechanical properties of cast Ti48Al6Nb x Si alloys. China Foundry, 17(6), 416-422. https:// doi.org/10.1007/s41230-020-0099-y

16. $\mathrm{Xu}, \mathrm{R}$. and Li, M., 2021. Deformability of $\beta$ phase in Ti-42.9Al-4.6 Nb-2Cr at elevated temperature. Journal of Alloys and Compounds, 871, 159617. https://doi.org/10.1016/j. jallcom.2021.159617 